Research Article

\title{
Development of Hypereutectic AlSi Alloy Powder Injection Molding Feedstocks by Rheological Analysis
}

\author{
Jiaqi Ni $(\mathbb{D}$, Keqing Han, and Muhuo Yu \\ State Key Laboratory for Modification of Chemical Fibers and Polymer Materials, College of Materials Science and Engineering, \\ Donghua University, Shanghai 201620, China
}

Correspondence should be addressed to Jiaqi Ni; nijiaqitop@163.com

Received 25 February 2018; Revised 2 May 2018; Accepted 14 May 2018; Published 26 June 2018

Academic Editor: Peter Majewski

Copyright ( 92018 Jiaqi Ni et al. This is an open access article distributed under the Creative Commons Attribution License, which permits unrestricted use, distribution, and reproduction in any medium, provided the original work is properly cited.

The comprehensive properties of a feedstock have a critical influence on the powder injection molding process. Proper feedstock with homogeneous structure, favorable flow characteristic, and moldability is the prerequisite for obtaining a final part with excellent comprehensive properties. The objective of the present work was to develop an optimal feedstock for fabrication of hypereutectic AlSi (20 wt.\%) alloy parts by the powder injection molding technique. For this purpose, micron-sized hypereutectic AlSi (20 wt.\%) alloy powder was mixed with different amounts of a binder which consisted of $35 \mathrm{wt} . \%$ high-density polyethylene, $62 \mathrm{wt} . \%$ carnauba wax, and $3 \mathrm{wt} . \%$ stearic acid. The binder contents of the feedstocks were in the range from 13 wt.\% to 21 wt.\%. The influences of binder content, shear rate, and temperature on the rheological behaviors of feedstocks have been investigated via a capillary rheometer. The feedstock with $21 \mathrm{wt} . \%$ binder exhibited a variable flow behavior and was culled. The rest of the feedstocks showed a pseudoplastic behavior. Comprehensive analysis of rheological parameters such as the flow behavior index, yield stress, flow activation energy, and the general moldability index, the feedstock with 17 wt.\% binder exhibited the best rheological performance and favorable moldability. The molded part with $17 \mathrm{wt} \%$ binder had constant density, good shape retention, and stiffness as well as homogeneous distribution of the powder and binder. After solvent debinding, the debound item showed a homogeneous porous structure which is suitable for the subsequent thermal debinding and sintering processes.

\section{Introduction}

AlSi alloys have a relatively low thermal expansion coefficient and density, high wear resistance, and excellent thermal conductivity and have been extensively used in automotive, aerospace, and electronics industries [1, 2]. These alloys are generally produced by the casting process due to their excellent fluidity, low shrinkage, good hot tear resistance, and feeding characteristics. However, if not properly chemically refined or rapidly solidified, conventionally casted hypereutectic AlSi alloy would have a large number of coarse and irregular lumps of primary silicon which shows detrimental effects on the comprehensive mechanical properties. More importantly, trends toward miniaturization of electronic components require aluminum alloy products possessing more complex geometries and smaller sizes. These requirements are difficult to meet with a conventional ingot metallurgy technology. Consequently, many efforts have been made to fabricate AlSi alloys and their composites via a variety of technological processes, such as traditional powder metallurgy $[3,4]$, the selective laser melting [5], the spray shaping technology [6], and the pressure infiltration method [7]. Among various techniques, the powder injection molding (PIM) is a special and promising technology for manufacturing AlSi alloys with small sizes, delicate shapes, and complex geometries $[8,9]$.

PIM is a developing net shaping technology by which metal/ceramic components with small sizes and complex geometries can be fabricated via batch production $[10,11]$. Generally, PIM technology involves four basic steps: feedstock preparation, injection molding, debinding, and sintering. The feedstock is a blend of powder particles and the molten polymer binder system in a proper ratio. During the injection molding process, the feedstock is injected into 


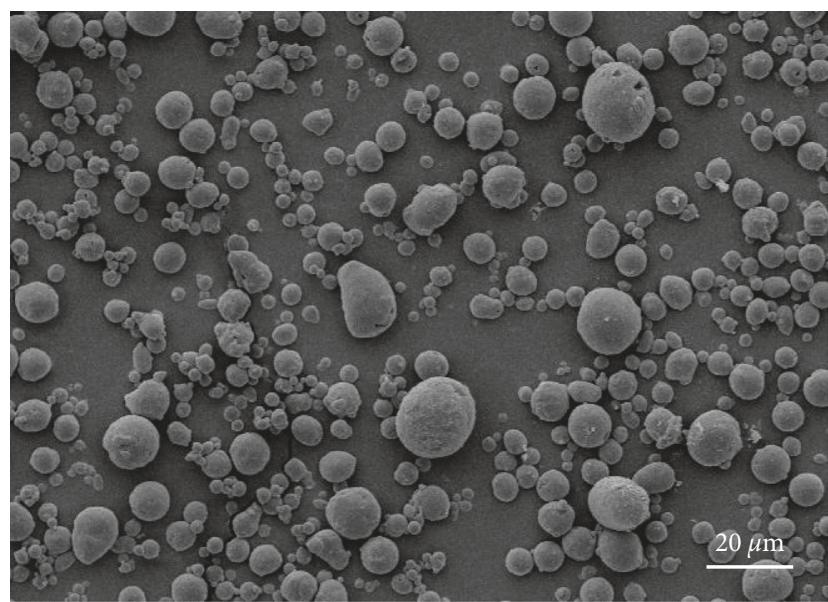

(a)

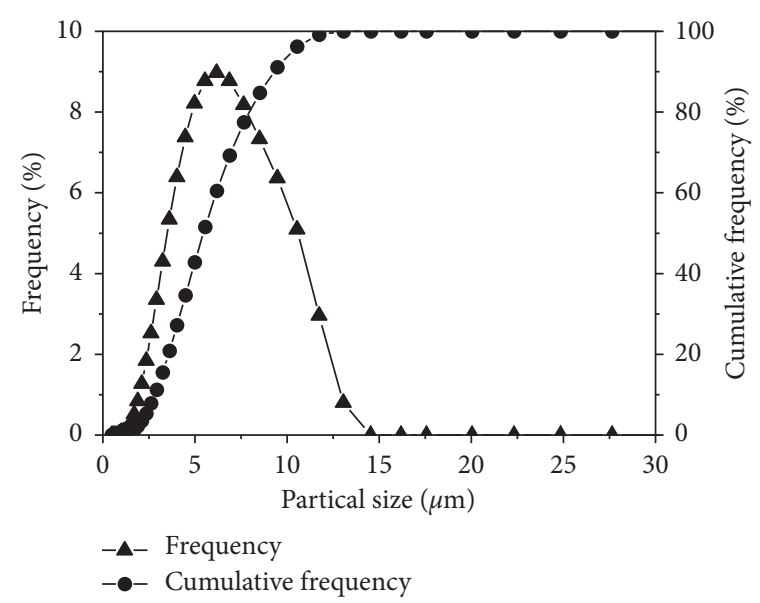

(b)

Figure 1: (a) Morphology of the AlSi alloy powder; (b) size distribution of the AlSi alloy powder.

TABle 1: Characteristics of binder components used in this work.

\begin{tabular}{lccc}
\hline Binder component & Supplier & Density $\left(\mathrm{g} / \mathrm{cm}^{3}\right)$ & Melting point $\left({ }^{\circ} \mathrm{C}\right)$ \\
\hline HDPE & ExxonMobil, USA & 0.956 & 122.6 \\
CW & Foncepi, Brazil & $0.990-0.999$ & 84.9 \\
SA & Sinopharm, China & 0.9408 & 57.6 \\
\hline
\end{tabular}

a mold to form a molded part with the desired geometry. Subsequently, the binder of molded parts is removed by a solvent, thermal, or another debinding process. Finally, the debound items maintaining the geometry shapes are sintered to a full or near a full density. The binder system in a feedstock acts as a temporary phase to enhance the compressibility and fluidity of powder in the injection molding process. It promotes the feedstock filling an entire mold cavity to provide a high quality of molded parts [12]. Feedstock quality is critical to the whole process of PIM. A homogeneous composition without separation and particles agglomeration and of good flow properties is the key point of an ideal feedstock. The rheological performance of the molten feedstock implies its flow ability. It strongly depends on the feedstock composition, powder and binder components properties, testing temperature, and the shear rate [13]. Hence, elucidating the dependence of the feedstock rheological characteristics on temperature, shear rate, and the binder content is the fundamental of the high-quality injection molding process and reduction of typical molding defects [14].

The present work aims at developing an ideal feedstock for the hypereutectic AlSi (20 wt.\%) alloy powder injection molding. The feedstock was composed of AlSi (20 wt.\%) alloy powder and a multicomponent binder system based on high-density polyethylene (HDPE), carnauba wax (CW), and stearic acid (SA). The influences of binder content, shear rate, and temperature on the rheological behaviors of feedstocks have been investigated via a capillary rheometer. Rheological parameters including the flow behavior index $(n)$, yield stress $(\sigma)$, flow activation energy $(E)$, and the general moldability index $\left(\alpha_{\text {stv }}\right)$ were calculated and discussed. Ultimately, the critical and optimum binder contents were identified. And the homogeneities of powder and binder distribution in the molded parts were investigated.

\section{Materials and Methods}

2.1. Materials. In this study, commercial air atomized AlSi (20wt.\%) alloy powders (Jiweixin Metal Powder Co., China) with particle sizes $D_{10}=2.93 \mu \mathrm{m}, D_{50}=5.73 \mu \mathrm{m}$, and $D_{90}=9.76 \mu \mathrm{m}$ were utilized. The morphology of the alloy powder and its granule size distribution is shown in Figure 1. A small amount of pure $\mathrm{Sn}$ and $\mathrm{Mg}$ powders were added (used as aids in the sintering process). The binder system was composed of $35 \mathrm{wt} \% \mathrm{HDPE}, 62 \mathrm{wt} \% \mathrm{CW}$, and 3 wt.\% SA. Table 1 presents the main characteristics of binder components.

2.2. Methods. The feedstock was prepared using the hot solvent mixing method. The preparing process is schematically illustrated in Figure 2. The premixed binder ingredients were added in a flask with xylene at $110^{\circ} \mathrm{C}$ and stirred. After all the ingredients dissolved completely, solid powders were gradually added to achieve the desired powder loading and continually stirred for 1 hour. Finally, xylene was distilled off; the homogeneous feedstock slurry was acquired and then pelleted. The feedstock compositions are listed in Table 2.

The rheological behavior of a feedstock critically influences on the injection molding process [15]. In this study, feedstock rheological properties were evaluated by viscosity 


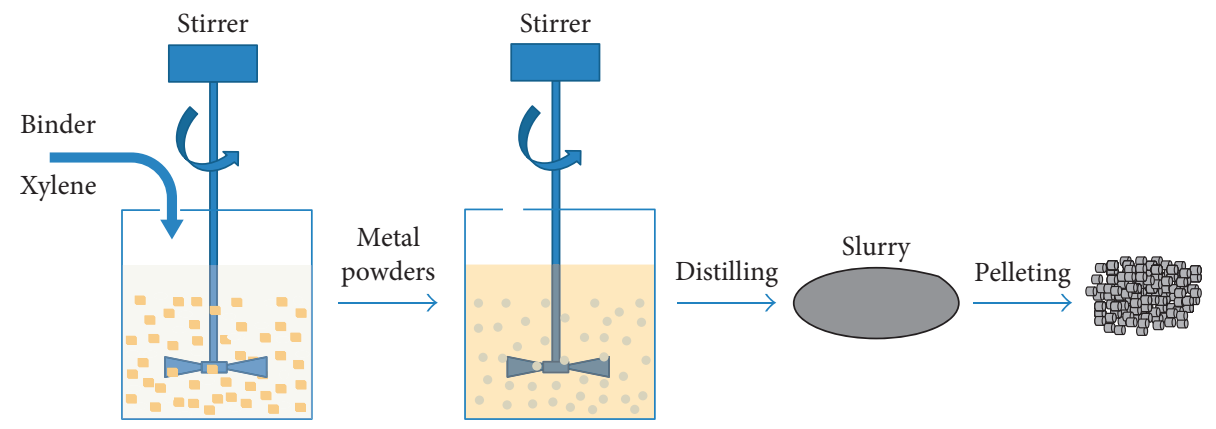

FIgure 2: The flowchart of the feedstocks preparation process.

TABLE 2: Feedstock compositions used in this work.

\begin{tabular}{lccccc}
\hline Feedstock label & B13 & B15 & B17 & B19 & B21 \\
\hline Binder content (wt.\%) & 13 & 15 & 17 & 19 & 21 \\
AlSi alloy powder (wt.\%) & 84 & 82 & 80 & 78 & 76 \\
Mg powder (wt.\%) & 1 & 1 & 1 & 1 & 1 \\
Sn powder (wt.\%) & 2 & 2 & 2 & 2 & 2 \\
\hline
\end{tabular}

measurements with a capillary rheometer (Malvern Rosand $\mathrm{RH} 2000, \mathrm{UK})$ in the temperature range of $130-170^{\circ} \mathrm{C}$. The capillary rheometer had a diameter of $0.5 \mathrm{~mm}$ and a length of $20 \mathrm{~mm}$, giving the length-to-radius ratio $(L / D)$ of 40 to achieve a laminar flow along the die and minimizing the entry and exit effects [16, 17]. Rheological tests were performed with the shear rate ranging from 10 to $2000 \mathrm{~s}^{-1}$, which covers the major range of the typical shear rates occurring in the PIM process $[18,19]$.

The injection molding process was performed with the five feedstocks listed in Table 2 using the injection molding machine (LX-MIM128, L $\Lambda$ SUM, China). Scanning electrical microscope (SEM, Hitachi SU-8010, Japan) was used to investigate the microstructure of the molded parts. To examine the homogeneity of the binder-powder distribution in the molded parts of feedstock B17, dynamic rheological measurement with a rheometer (ARES-RFS), TG analyses using a thermal analyzer (TGA, Q5000IR), and density measurements with a densitometer (Quantachrome UPY20T) were performed. Dynamic rheological measurements were carried out with molded samples of $25 \mathrm{~mm}$ in diameter and $2 \mathrm{~mm}$ in thickness with feedstock B17. TGA tests were performed with five samples randomly selected from a molded part and heated from 50 to $600^{\circ} \mathrm{C}$ with a heating rate of $10^{\circ} \mathrm{C} / \mathrm{min}$ in a nitrogen atmosphere. Density measurements were conducted from five random molded parts using a nitrogen pycnometer (Quantachrome UPY-20T).

\section{Results and Discussion}

3.1. Rheological Properties. Shear rate dependence of the feedstock viscosity at all test temperatures is shown in Figure 3. In most tests, the apparent viscosity decreased with the shear rate increase, which indicated the pseudoplastic fluid. It was suggested that the orientation and ordering of particles in the polymer flow occurred. The apparent viscosity values of the feedstock with the binder content of $21 \mathrm{wt} . \%$ varied at high shear rates when the temperature was equal to or higher than $150^{\circ} \mathrm{C}$. This might take place due to the powder and binder separation during the rheological tests with the exceeded binder content [20]. In general, at a given temperature, the relationship between the viscosity and the shear rate of a pseudoplastic fluid is described by the power law [21]:

$$
\eta=K \dot{\gamma}^{n-1}
$$

where $\eta$ is the shear viscosity, $\dot{\gamma}$ is the shear rate, $K$ is a constant, and $n$ is the power law exponent. For pseudoplastic fluids, $n$ is less than 1 , and its value indicates the shear rate dependence of the viscosity. The lower value of $n$ relates to the higher sensitivity of viscosity to the shear rate $[22,23]$. The feedstocks having low $n$ values were considered for using in the PIM process [24]. From (1), $n$ can be calculated from the slope of the $\log (\eta)$ versus $\log (\dot{\gamma})$ curve. The power law exponents at $150^{\circ} \mathrm{C}$ for the feedstocks with different binder contents are calculated and presented in Table 3. One may see that the value of $n$ decreased with the increase of binder content from 13 to 17 wt.\%. While as the binder content continue to increase to $19 \mathrm{wt} . \%$, the value of $n$ increased. The feedstock with 17 wt.\% binder had the lowest power law exponent, and therefore, such a value was considered to be the optimal binder content for the PIM feedstock.

The minimum stress value required for initiation of the molten feedstock flow is termed as yield stress [25]. In our study, the Casson model [26] was used to calculate the yield stress values of feedstocks with different binder contents at temperatures ranging from 130 to $170^{\circ} \mathrm{C}$, and the results are shown in Figure 4. As can be seen from Figure 4, the yield stress decreased as the binder content and the temperature increased. When the binder content was over $15 \mathrm{wt} . \%$ and the temperature exceeded $140^{\circ} \mathrm{C}$, the yield stress was below $8 \mathrm{kPa}$. The values were equal to or somewhat less than those reported earlier in [27, 28]. Hayat et al. [27] developed a titanium feedstock with the binder system mainly composed of PEG and PMMA. For the feedstock that finally was successfully injected, the yield stress value exceeded $40 \mathrm{kPa}$ at all test temperatures. Romero and Herranz [28] investigated the influence of the vanadium carbide additive on the rheological behavior of AlSiM2 high-speed steel PIM feedstocks, and yield stress values less than $6 \mathrm{kPa}$ were 

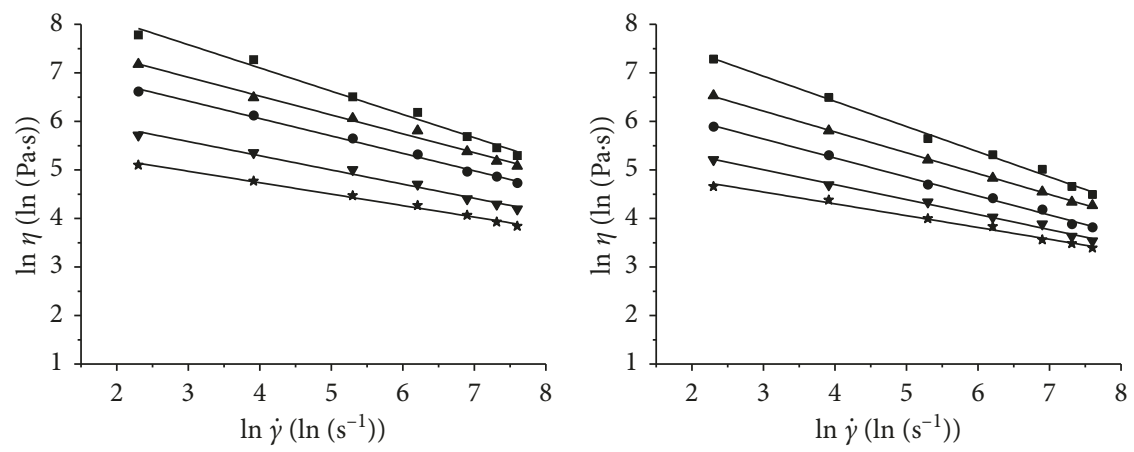

- $130^{\circ} \mathrm{C}$

- $160^{\circ} \mathrm{C}$

- $130^{\circ} \mathrm{C}$

- $160^{\circ} \mathrm{C}$

- $140^{\circ} \mathrm{C}$

* $170^{\circ} \mathrm{C}$

- $140^{\circ} \mathrm{C}$

* $170^{\circ} \mathrm{C}$

- $150^{\circ} \mathrm{C}$

- $150^{\circ} \mathrm{C}$

(a)

(b)
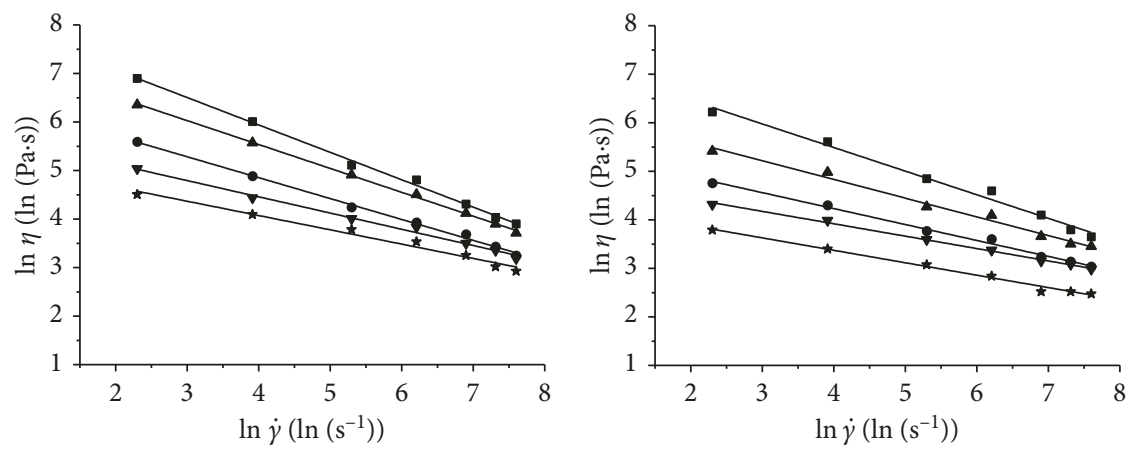

- $130^{\circ} \mathrm{C}$

- $160^{\circ} \mathrm{C}$

- $130^{\circ} \mathrm{C}$

- $160^{\circ} \mathrm{C}$

- $140^{\circ} \mathrm{C}$

* $170^{\circ} \mathrm{C}$

- $140^{\circ} \mathrm{C}$

* $170^{\circ} \mathrm{C}$

- $150^{\circ} \mathrm{C}$

- $150^{\circ} \mathrm{C}$

(c)

(d)

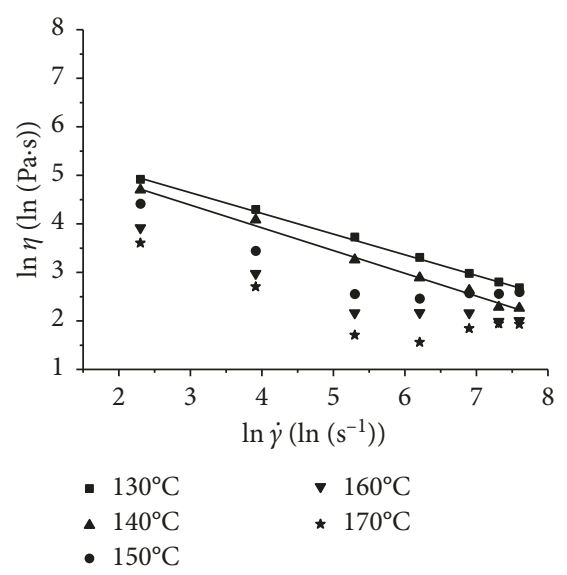

(e)

Figure 3: Shear rate dependence of the viscosity of the feedstock: (a) B13, (b) B15, (c) B17, (d) B19, and (e) B21 at different temperatures.

TABle 3: Comparison of $n, E, B$, and $\eta_{0}$ values in feedstocks with different binder contents.

\begin{tabular}{lcccc}
\hline Binder content (wt.\%) & 13 & 15 & 17 & 19 \\
\hline$n$ & 0.6406 & 0.6084 & 0.5695 & 0.6716 \\
$E(\mathrm{~kJ} / \mathrm{mol})$ & 62.46 & 53.11 & 40.65 & 53.42 \\
$B(\mathrm{~Pa} \cdot \mathrm{s})$ & $2.565 \times 10^{-6}$ & $1.89 \times 10^{-5}$ & $4.118 \times 10^{-4}$ & $7.05 \times 10^{-6}$ \\
$\eta_{0}(\mathrm{~Pa} \cdot \mathrm{s})$ & 143.42611 & 65.78027 & 39.71981 & 25.40155 \\
\hline
\end{tabular}




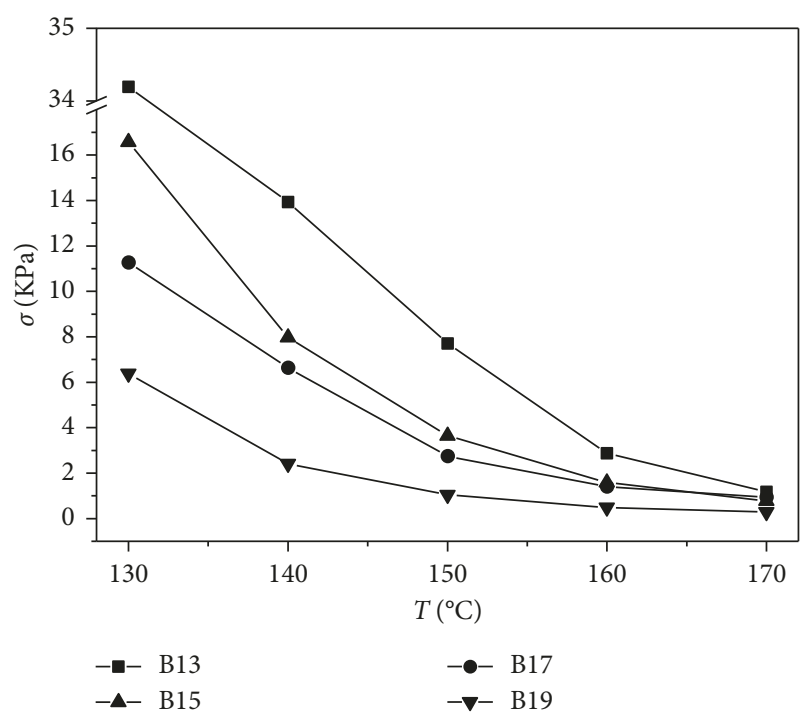

FIgURE 4: Temperature dependence of the yield stress of feedstocks with different binder contents.

obtained for three selected feedstocks which were appropriate for the molding process.

Typically, the rheological performance of PIM feedstocks is temperature-dependent; the apparent viscosity decreased with the temperature increased as Figure 3 shows. Due to an expansion of the binder system and disentangling molecular chains at heating, flow facilitated [29]. In general, at a constant shear rate, the relationship between the viscosity and temperature can be described by the Arrhenius-type expression as follows [21]:

$$
\eta=B \exp \left(\frac{E}{R T}\right),
$$

where $B$ is the viscosity at the reference temperature, $E$ is the flow activation energy, $T$ is the temperature in Kelvin, and $R$ is the gas constant. The temperature dependence of the viscosity can be estimated by the value of $E$. At the lower $E$ value, the feedstock is less sensitive to a temperature, which allows maintaining the stability of viscosity at temperature fluctuations during the injection molding process, and helps to avoid stress concentrations, cracks, and distortions in the molded parts [21, 22].

According to (2), at a given shear rate, the flow activation energy can be obtained from the slope of $\ln \eta$ versus $1 / T$ curves. In this work, $\ln \eta$ versus $1 / T$ curves are plotted in Figure 5 at the shear rate of $1000 \mathrm{~s}^{-1}$, and $E$ values are calculated and summarized in Table 3 . The value of $E$ decreased first when the binder content increased from 13 to $17 \mathrm{wt} . \%$, and then, the activation energy increased for 19 wt.\% binder content. As shown in Table 3, the feedstock with $17 \mathrm{wt} . \%$ binder content had the lowest value of $E=40.65 \mathrm{~kJ} / \mathrm{mol}$, which implied that the optimum binder content based on the temperature sensitivity was $17 \mathrm{wt} . \%$.

\subsection{Determination of the Critical Binder Content.} Figure 6 presents the evolution of rheological parameters, $n$, $B$, and $E$ with variations of the binder content at reference

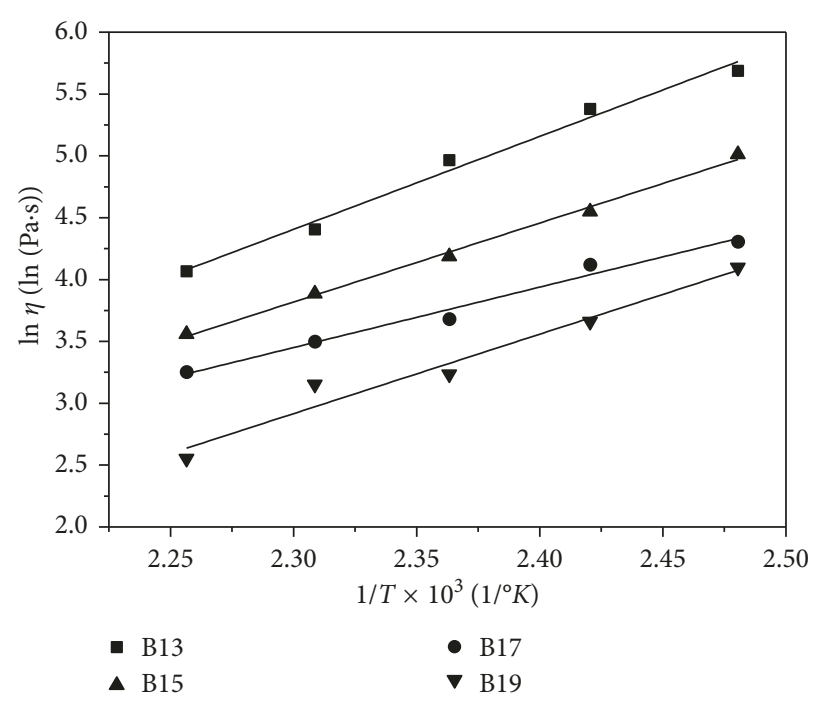

FIGURE 5: Temperature dependencies of feedstocks viscosity at the shear rate of $1000 \mathrm{~s}^{-1}$.

conditions of $150^{\circ} \mathrm{C}$ and $1000 \mathrm{~s}^{-1}$. From Figure 6, the typical zone of the critical binder content can be estimated [30,31]. A region of significant changes in all rheological parameters occurred at $16-18$ wt.\% binder content. This range can be regarded as the critical binder content region. The feedstock with $17 \mathrm{wt} . \%$ binder content had the minimum activation energy, the highest value of reference viscosity, and an inflection in the power law exponent value. Thus, we considered this value as the optimal binder content and used it for the injection molding process.

3.3. General Rheological Properties. In general, feedstocks possessing both high shear sensitivity and weak temperature dependence exhibit preferable rheological properties for PIM. In many investigations, rheological parameters like $\eta$, $n$, and $E$, described above, were separately assessed and gave unclear or incomplete insights into determination of the optimal binder content. To combine all the factors and systematically describe general rheological properties of a feedstock, the general moldability index $\alpha_{\text {stv }}$ was introduced as follows [32]:

$$
\alpha_{\mathrm{stv}}=\frac{1}{\eta_{0}} \cdot \frac{|\partial \log \eta / \partial \log \dot{\gamma}|}{\partial \log \eta / \partial(1 / T)}=\frac{1}{\eta_{0}} \cdot \frac{1-n}{E / R},
$$

where $\eta_{0}$ is the reference viscosity (at $150^{\circ} \mathrm{C}$ and shear rate of $1000 \mathrm{~s}^{-1}$ in this study). The values are shown in Table 3 . The subscripts $s, t$, and $v$ correspond to the shear sensitivity, temperature sensitivity, and viscosity, respectively. According to this theory, a higher value of $\alpha_{\text {stv }}$ means better rheological properties [30]. The $\alpha_{\text {stv }}$ values of different feedstocks are presented in Figure 7. As is shown, the feedstock with $17 \mathrm{wt} . \%$ binder content had the highest moldability index. It can be concluded that the feedstock with 17 wt.\% binder content had the most favorable rheological properties, which was thus considered as the optimal binder content. 


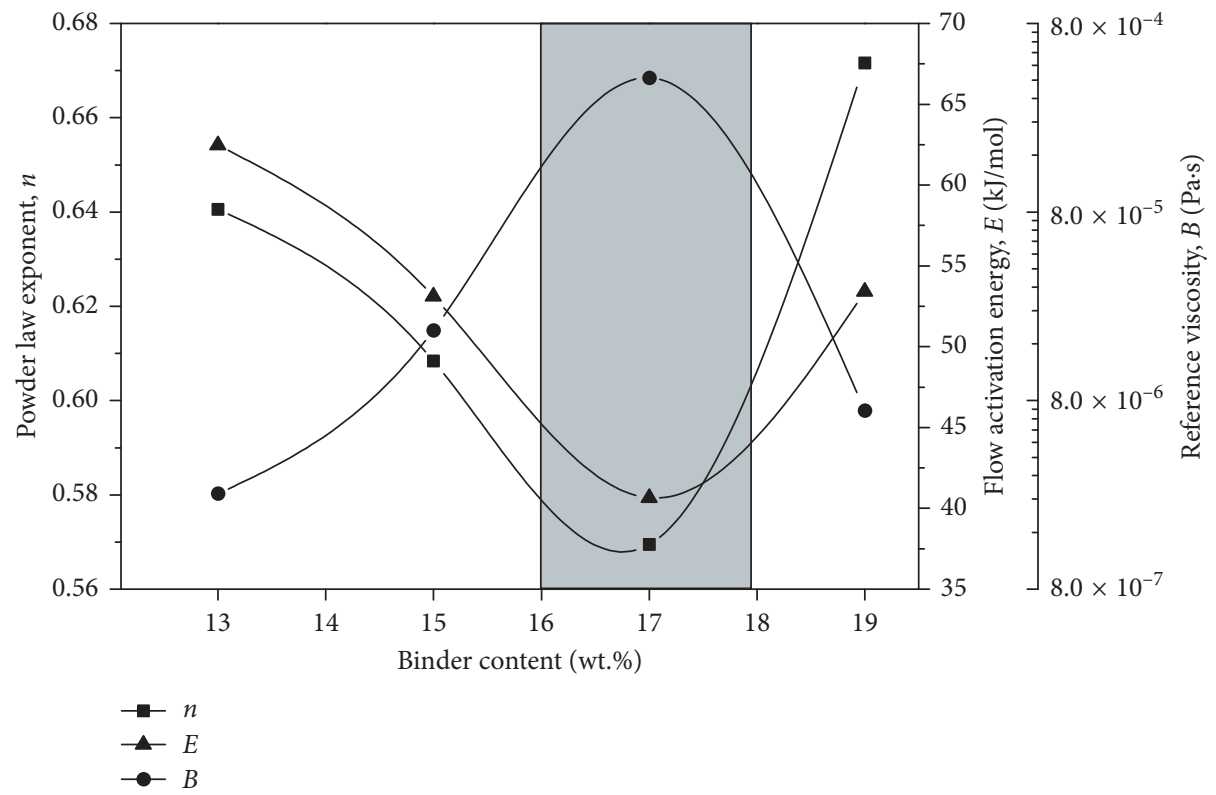

FIgURE 6: Determination of the critical binder content region.

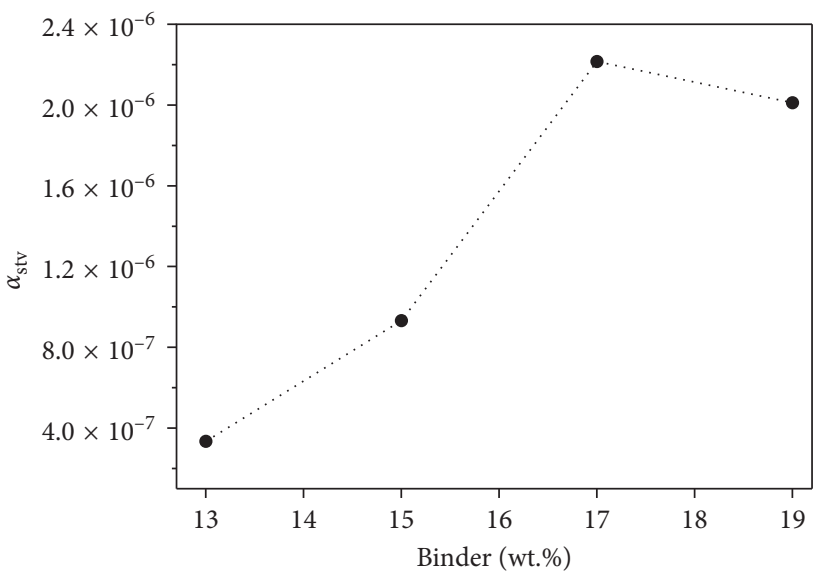

Figure 7: General moldability index versus binder content wt.\%.

3.4. Injection Molding and Homogeneity Analysis. We performed the injection molding process with the five feedstocks listed in Table 2. The injection molded part of feedstock B17 presented in Figure 8(a) exhibits good shape retention without apparent macroscopic defects such as gas entrapment, voids, shorts, and sinks. And after the solvent debinding, the part had good dimensional stability and excellent shape retainability.

SEM micrographs of molded parts are shown in Figure 8. One may see from Figure 8(b) that the feedstock with $13 \mathrm{wt} . \%$ binder exhibits binder-powder separation in the molded part due to the lack of binder. When the binder content was increased to $15 \mathrm{wt} . \%$, part of the fracture surface still lacks binder, as shown in Figure 8(c). As the binder content increased to $17 \mathrm{wt} . \%$, the powders were homogeneously dispersed in the binder, as shown in Figure 8(d). When the binder content was increased continuously to $19 \mathrm{wt} . \%$ and $21 \mathrm{wt} . \%$, as shown in Figures 8(e) and 8(f), the exceeding binder was observed. This may cause binder-powder separation during the mixing and injection molding process. Figure $8(\mathrm{~g})$ presents the microstructure of solvent debound part of B17. A homogeneous porosity of the product is good for the residual binder removing by subsequent thermal debinding and sintering processes.

Dynamic rheology measurement was performed to verify the homogeneity of injection molded parts of feedstock B17. The viscosity and torque values dropped quickly at the beginning of the test, as shown in Figure 9, and this may be related to the loss of feedstock structure [33]. Thereafter, the viscosity and torque values remained constant with time, which revealed that the feedstock was mixed uniformly and the structure of the molded items was homogeneous [34].

Thermogravimetric analysis and pycnometer density measurement of the molded parts were performed to further examine the homogeneity of the powder-binder distribution. TGA curves shown in Figure 10 revealed that the binder started slow decomposition at about $280^{\circ} \mathrm{C}$ in all the samples, and then, a rapid weight loss followed and finally completed at about $590^{\circ} \mathrm{C}$. Five curves displayed the same behavior and overlapped. The total weight loss of all samples reached about $16.88 \mathrm{wt} . \%$, which was close to the binder content value of $17 \mathrm{wt} . \%$, implying that the powder and binder were distributed uniformly in the molded part. Figure 11 compares the measured densities of five injected molded parts of B17. The average density of the molded parts was $2.0687 \mathrm{~g} / \mathrm{cm}^{3}$, and the standard variation was 0.00129 . This indicates the homogeneity of feedstocks and the homogeneous structure of injection molded parts.

\section{Conclusions}

A comprehensive study regarding the rheological behavior of AlSi (20 wt.\%) alloy powder-polymer mixture was performed. The feedstocks showed the pseudoplastic behavior 


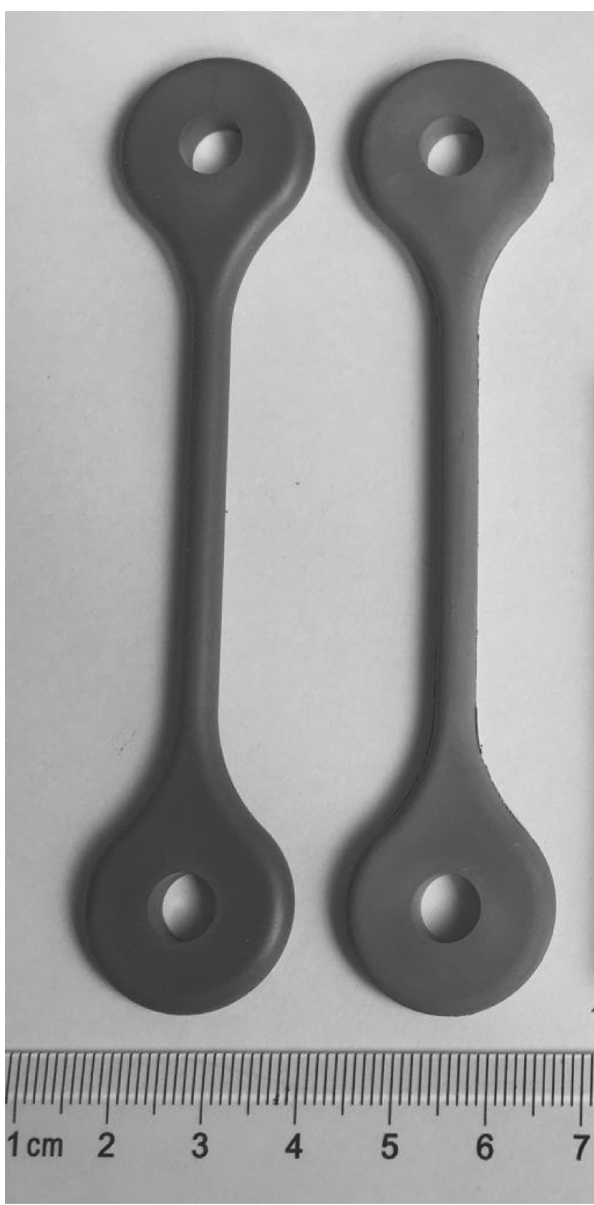

(a)

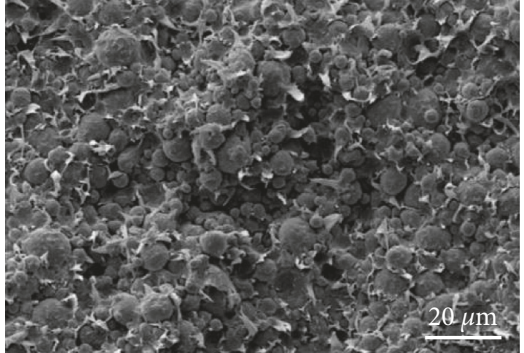

(b)

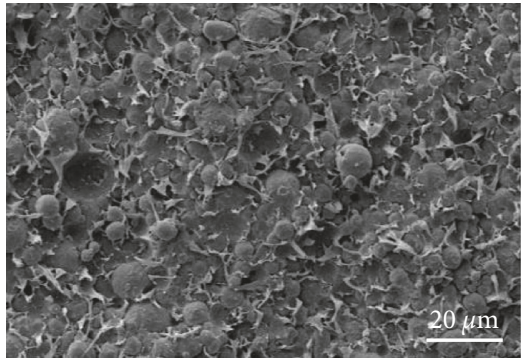

(d)

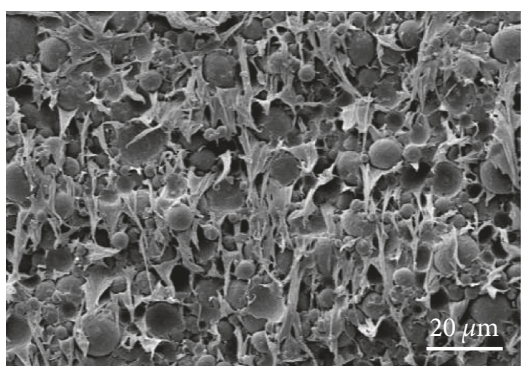

(f)

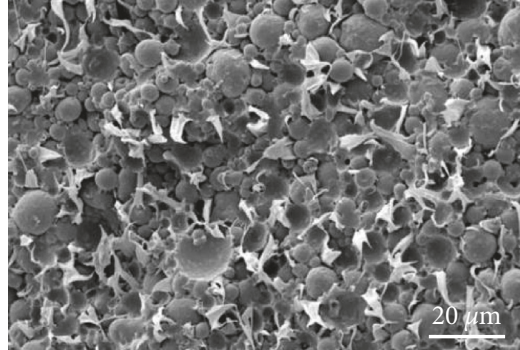

(c)

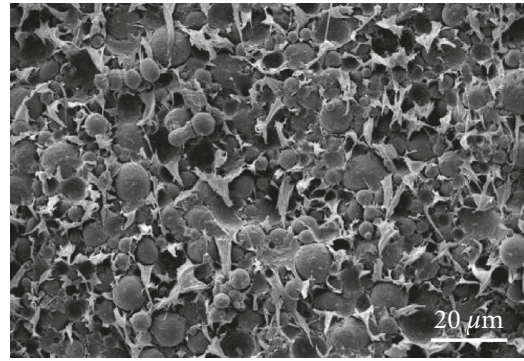

(e)

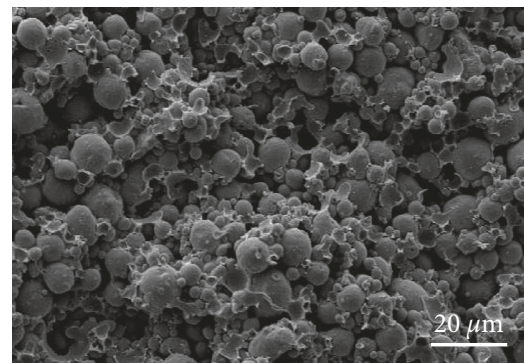

(g)

FIGURE 8: (a) Image of the injected crude product (left) and the solvent debound product (right) of B17; SEM micrographs of injected crude products of B13 (b), B15 (c), B17 (d), B19 (e), and B21 (f); (g) SEM micrograph of the solvent debound product of B17.

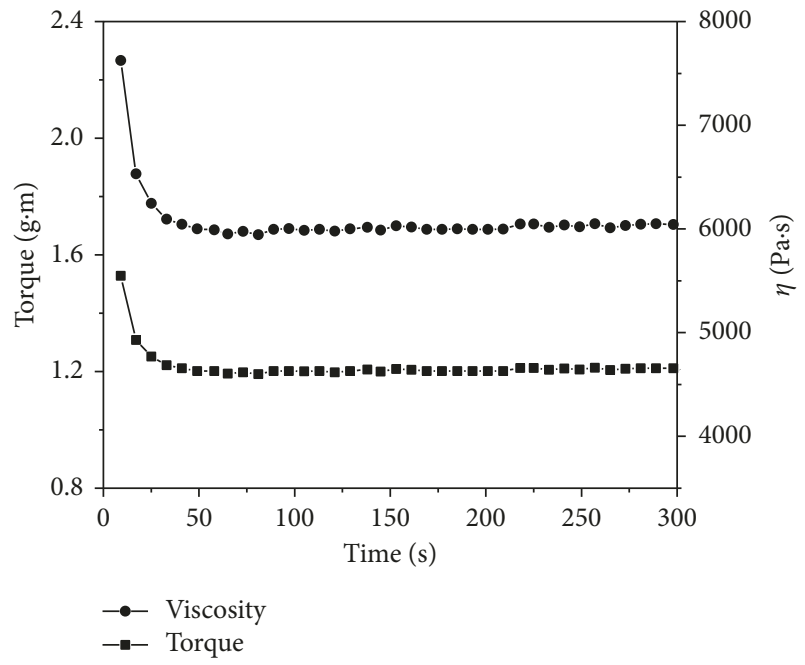

Figure 9: Viscosity and torque values of the feedstock B17 at $150^{\circ} \mathrm{C}$.

with the increase of shear rate, which is desirable for PIM. The feedstock with $17 \mathrm{wt} . \%$ binder content had optimal rheological properties based on the analysis of the power law exponent, flow activation energy, reference viscosity, and the

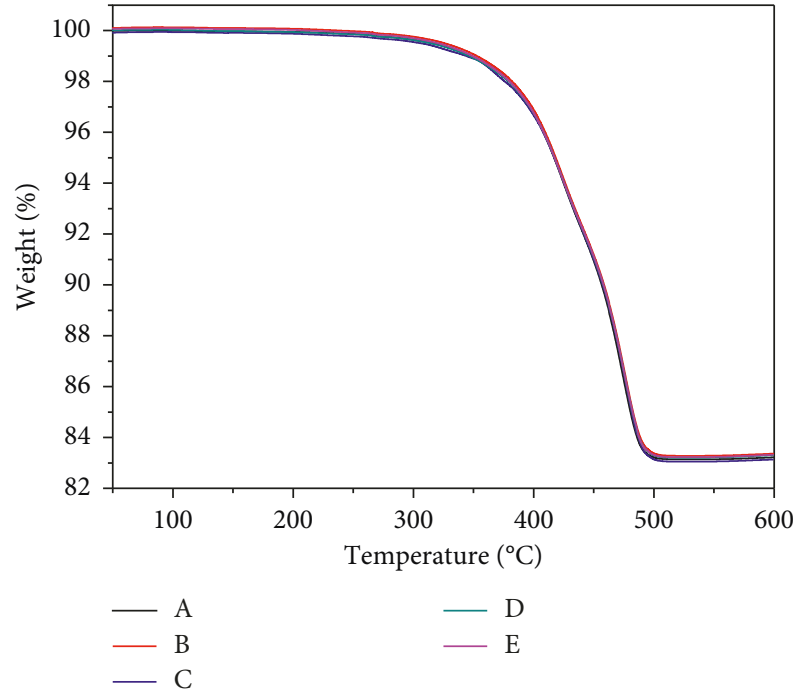

FIGURE 10: TGA curves of 5 crude products.

general moldability index. The injection molding process of the optimal feedstock proved that the selected feedstock composition had excellent injection molding performance. 


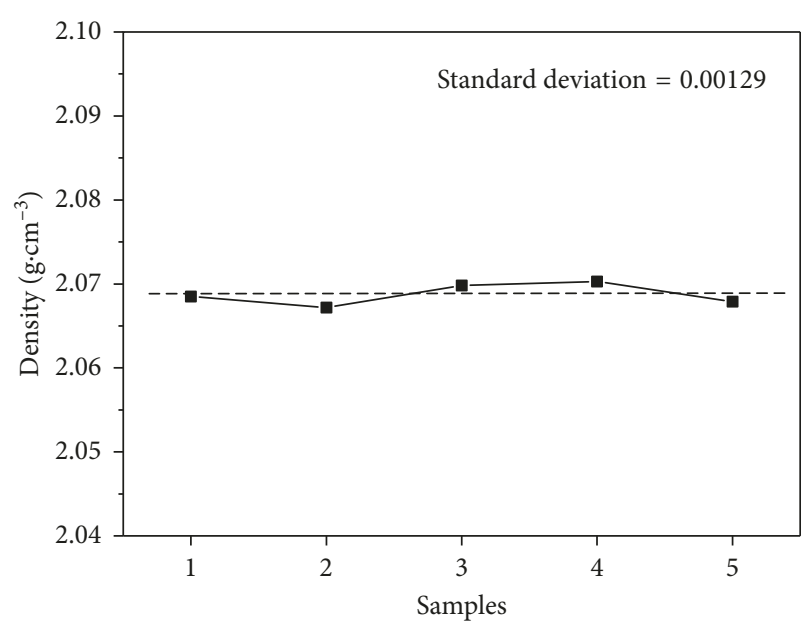

FIGURE 11: Densities of the molded parts of feedstock B17.

The results of SEM observation, dynamic rheological measurement, TGA analysis, and the density measurement revealed a homogeneous powder and binder distribution in the molded parts of the optimal feedstock.

\section{Data Availability}

The data supporting the findings of this study are currently under embargo while the whole research processes of "Development of Hypereutectic AlSi Alloy Powder Injection Molding Process" are completed, and the research findings are commercialized. At that time, requests for data will be considered by the corresponding author.

\section{Conflicts of Interest}

The authors declare that there are no conflicts of interest regarding the publication of this paper.

\section{Acknowledgments}

This work was financially supported by the State Key Laboratory for Modification of Chemical Fibers and Polymer Materials, College of Materials Science and Engineering, Donghua University.

\section{References}

[1] J. G. Jung, T. Y. Ahn, Y. H. Cho, S. H. Kim, and J. M. Lee, "Synergistic effect of ultrasonic melt treatment and fast cooling on the refinement of primary $\mathrm{Si}$ in a hypereutectic Al-Si alloy," Acta Materialia, vol. 144, pp. 31-40, 2017.

[2] C.-D. Li, C.-H. Sun, W.-Q. Si, M. Zhao, M.-M. Lu, and L. Zhang, "Effects of ZnS modification on primary $\mathrm{Si}$ in hypereutectic Al-Si alloy," China Foundry, vol. 14, no. 2, pp. 93-97, 2017.

[3] H. S. Jailani, A. Rajadurai, B. Mohan, and T. Sornakumar, "Sliding wear behaviour of Al-Si alloy-fly ash composites produced by powder metallurgy technique," Industrial Lubrication and Tribology, vol. 69, no. 2, pp. 241-247, 2017.

[4] C. F. John, R. C. Paul, S. C. E. Singh, and T. Ramkumar, "Tribological behavior, mechanical properties and microstructure of $\mathrm{Al}-12 \mathrm{Si}-\mathrm{ZrC}$ composite prepared by powder metallurgy," Bulletin of the Polish Academy of Sciences Technical Sciences, vol. 65, no. 2, pp. 149-154, 2017.

[5] N. Kang, P. Coddet, L. Dembinski, H. Liao, and C. Coddet, "Microstructure and strength analysis of eutectic Al-Si alloy in-situ manufactured using selective laser melting from elemental powder mixture," Journal of Alloys and Compounds, vol. 691, pp. 316-322, 2017.

[6] E. O. Olakanmi, M. Tlotleng, C. Meacock, S. Pityana, and M. Doyoyo, "Deposition mechanism and microstructure of laser-assisted cold-sprayed (LACS) Al-12 wt.\% Si coatings: effects of laser power," JOM, vol. 65, no. 6, pp. 776-783, 2013.

[7] A. Shaga, P. Shen, C. Sun, and Q. Jiang, "Lamellarinterpenetrated $\mathrm{Al}-\mathrm{Si}-\mathrm{Mg} / \mathrm{SiC}$ composites fabricated by freeze casting and pressureless infiltration," Materials Science and Engineering A, vol. 630, pp. 78-84, 2015.

[8] H. Saidin and M. Azuddin, "Preparation of aluminum feedstock for green part specimen using metal injection molding," Applied Mechanics and Materials, vol. 465-466, pp. 1250-1254, 2014.

[9] B. S. Zlatkov, E. Griesmayer, H. Loibl et al., "Recent advances in PIM technology I," Science of Sintering, vol. 40, no. 1, pp. 79-88, 2008.

[10] M. Aslam, F. Ahmad, K. Altaf, M. A. Omar, and R. M. German, "Powder injection molding of biocompatible stainless steel biodevices," Powder Technology, vol. 295, pp. 84-95, 2016.

[11] J.-X. Wen, T.-B. Zhu, Z.-P. Xie, W.-B. Cao, and W. Liu, “A strategy to obtain a high-density and high-strength zirconia ceramic via ceramic injection molding by the modification of oleic acid," International Journal of Minerals, Metallurgy, and Materials, vol. 24, no. 6, pp. 718-725, 2017.

[12] R. K. Enneti, V. P. Onbattuvelli, and S. V. Atre, "4-Powder binder formulation and compound manufacture in metal injection molding (MIM)," in Handbook of Metal Injection Molding, pp. 64-92, Elsevier, Berlin, Germany, 2012.

[13] H. Lobo, "8-characterization of feedstock in metal injection molding (MIM)," in Handbook of Metal Injection Molding, pp. 183-196, Elsevier, Berlin, Germany, 2012.

[14] S. V. Atre, T. J. Weaver, and R. M. German, Injection Molding of Metals and Ceramics, Metal Powder Industry, Princeton, NJ, USA, 1997.

[15] T. Zhang, Z. Jiang, J. Wu, and Z. Chen, "Influence of rheological behavior of ceramic mixes on injection molding of ceramic compacts," Journal of the American Ceramic Society, vol. 73, no. 7, pp. 2171-2175, 2010.

[16] M. Khakbiz, A. Simchi, and R. Bagheri, "Investigation of rheological behaviour of $316 \mathrm{~L}$ stainless steel-3 wt-\%TiC powder injection moulding feedstock," Powder Metallurgy, vol. 48, no. 2, pp. 144-150, 2005.

[17] J. Hidalgo, A. Jiménez-Morales, and J. M. Torralba, "Torque rheology of zircon feedstocks for powder injection moulding," Journal of the European Ceramic Society, vol. 32, no. 16, pp. 4063-4072, 2012.

[18] D. Li, H. Hou, Z. Tan, and K. Lee, "Metal injection molding of pure molybdenum," Powder Metallurgy Industry, vol. 20, no. 5, pp. $480-487,2008$.

[19] J. H. Wang, Q. N. Shi, W. U. Cheng-Ling, and X. I. Jian, "Rheological characteristics of injection molded titanium alloys powder," Transactions of Nonferrous Metals Society of China, vol. 23, no. 9, pp. 2605-2610, 2013.

[20] S. Tang, "Rheological characterization of powder injection molding compounds," Polimery, vol. 55, pp. 3-11, 2010.

[21] X. Chen, Y. C. Lam, Z. Y. Wang, and K. W. Tan, "Determination of phenomenological constants of shear-induced 
particle migration model," Computational Materials Science, vol. 30, no. 3-4, pp. 223-229, 2004.

[22] B. Huang, S. Liang, and X. Qu, "The rheology of metal injection molding," Journal of Materials Processing Technology, vol. 137, no. 1-3, pp. 132-137, 2003.

[23] Y. Li, B. Huang, and X. Qu, "Viscosity and melt rheology of metal injection moulding feedstocks," Powder Metallurgy, vol. 42, no. 1, pp. 86-90, 1999.

[24] P. Thomas-Vielma, A. Cervera, B. Levenfeld, and A. Várez, "Production of alumina parts by powder injection molding with a binder system based on high density polyethylene," Journal of the European Ceramic Society, vol. 28, no. 4, pp. 763-771, 2008.

[25] R. R. Huilgol and Z. You, "Application of the augmented Lagrangian method to steady pipe flows of Bingham, Casson and Herschel-Bulkley fluids," Journal of Non-Newtonian Fluid Mechanics, vol. 128, no. 2-3, pp. 126-143, 2005.

[26] N. Casson, "A Flow Equation for Pigment-Oil Dispersions of the Printing-Ink Type," in Proceedings of the Conference on Rheology of Disperse Systems, pp. 84-104, Swansea, UK, 1959.

[27] M. D. Hayat, G. Wen, M. F. Zulkifli, and P. Cao, "Effect of PEG molecular weight on rheological properties of Ti-MIM feedstocks and water debinding behaviour," Powder Technology, vol. 270, pp. 296-301, 2015.

[28] A. Romero and G. Herranz, "Development of feedstocks based on steel matrix composites for metal injection moulding," Powder Technology, vol. 308, pp. 472-478, 2017.

[29] L. Liu, N. H. Loh, B. Y. Tay, S. B. Tor, Y. Murakoshi, and R. Maeda, "Mixing and characterisation of 316L stainless steel feedstock for micro powder injection molding," Materials Characterization, vol. 54, no. 3, pp. 230-238, 2005.

[30] G. Aggarwal, S. J. Park, and I. Smid, "Development of niobium powder injection molding: part I. Feedstock and injection molding," International Journal of Refractory Metals and Hard Materials, vol. 24, no. 3, pp. 253-262, 2006.

[31] J. M. Contreras, A. Jiménez-Morales, and J. M. Torralba, "Experimental and theoretical methods for optimal solids loading calculation in MIM feedstocks fabricated from powders with different particle characteristics," Powder Metallurgy, vol. 53, no. 1, pp. 34-40, 2010.

[32] F. E. Weir, "Moldability of plastics based on melt rheology. Part 1-theoretical development," Polymer Engineering and Science, vol. 3, no. 1, pp. 32-36, 2010.

[33] A. Ghanbari, M. Alizadeh, E. Ghasemi, R. Y. Rad, and S. Ghaffari, "Preparation of optimal feedstock for lowpressure injection molding of $\mathrm{Al} / \mathrm{SiC}$ nanocomposite," Science and Engineering of Composite Materials, vol. 22, no. 5, pp. 549-554, 2015.

[34] R. Supati, N. H. Loh, K. A. Khor, and S. B. Tor, "Mixing and characterization of feedstock for powder injection molding," Materials Letters, vol. 46, no. 2-3, pp. 109-114, 2000. 


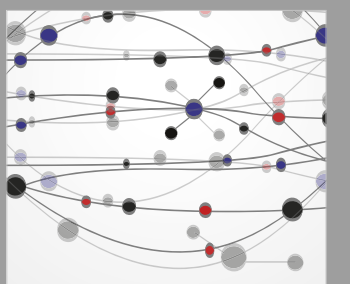

The Scientific World Journal
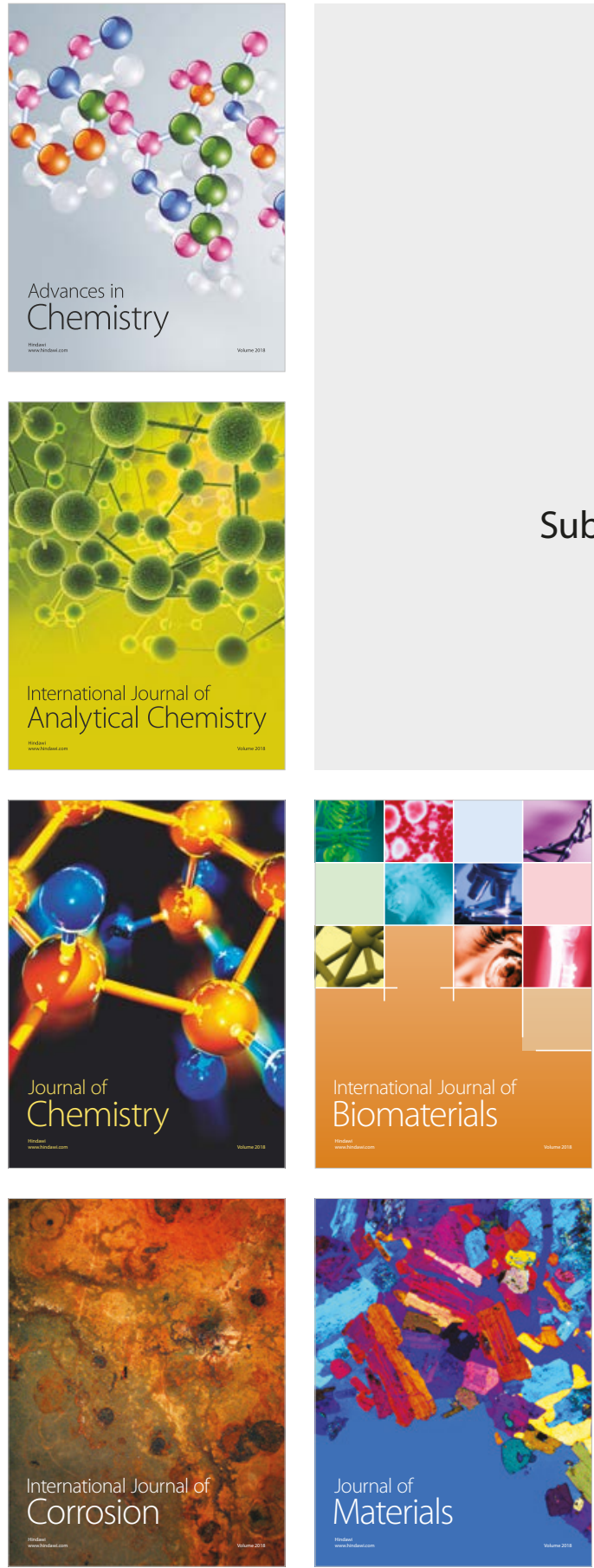

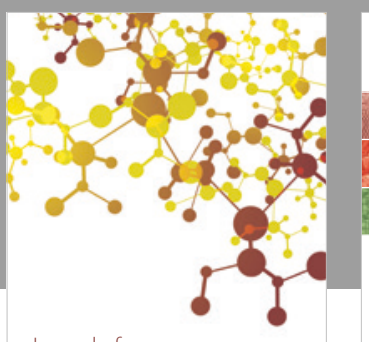

Journal of

Applied Chemistry
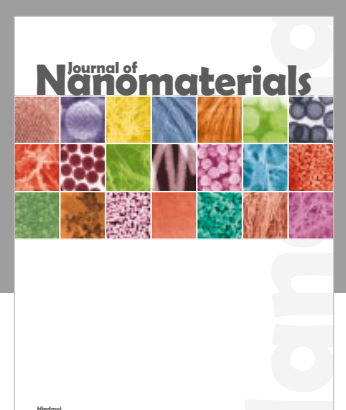

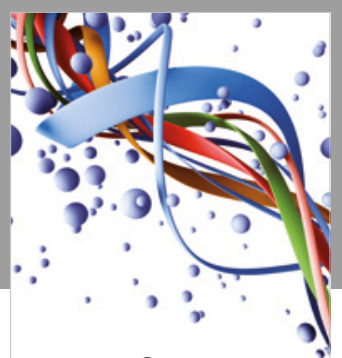

Scientifica

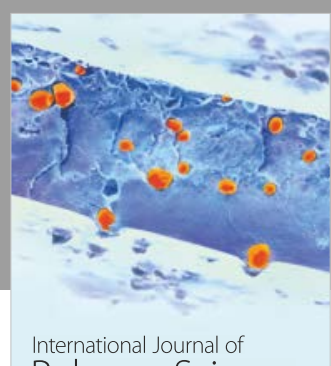

Polymer Science

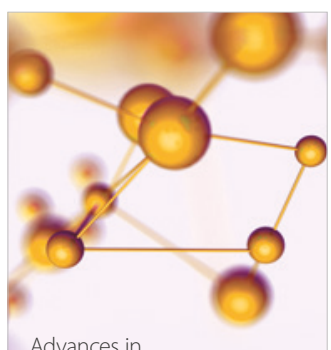

Physical Chemistry
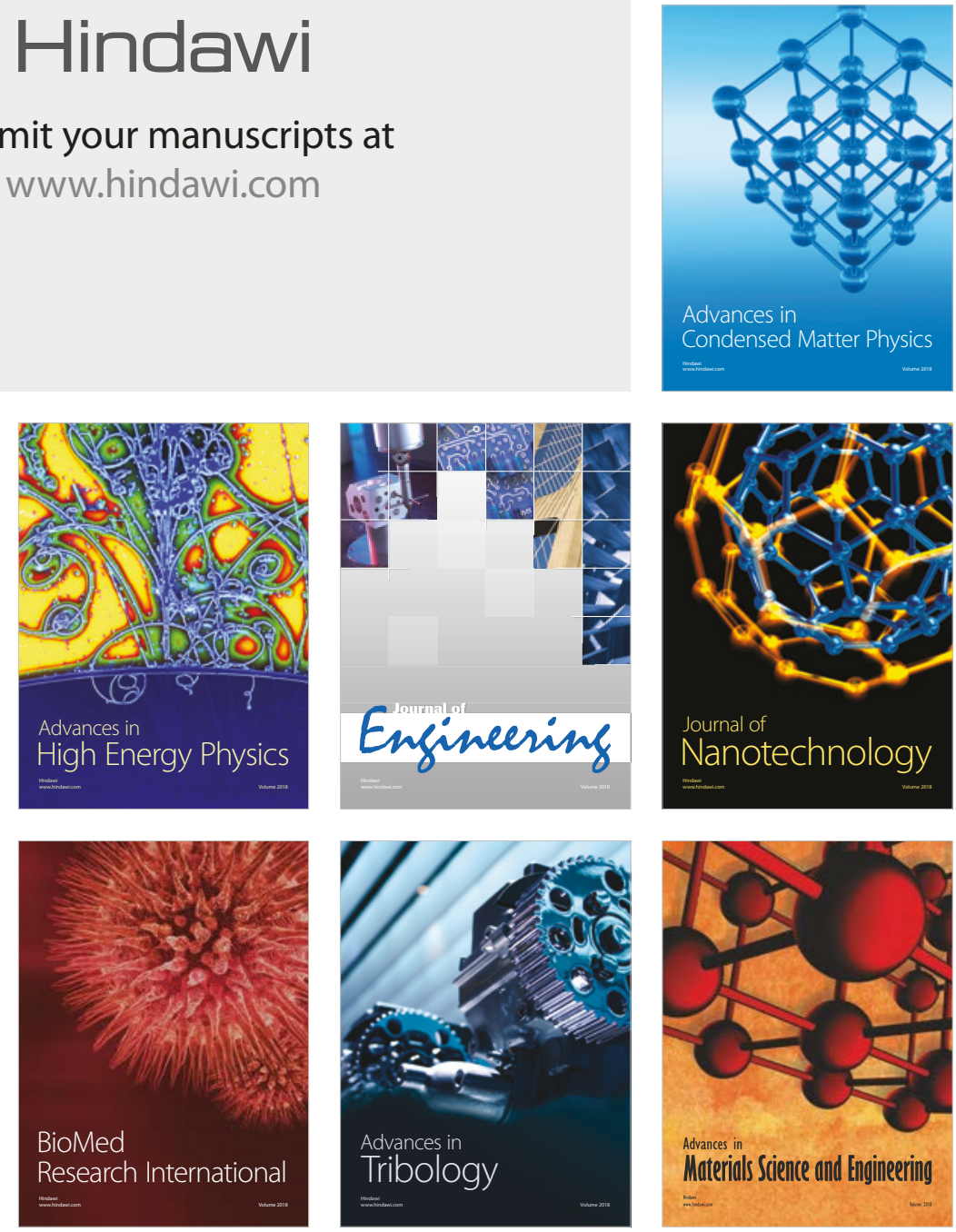